\title{
Heparinised intraocular infusion and bacterial contamination in cataract surgery
}

\author{
T D Manners, D P J Turner, P H Galloway, A M Glenn
}

\begin{abstract}
Backgroundlaims-Heparin in solution reduces bacterial adhesion to intraocular lenses and a lower incidence of postoperative endophthalmitis has been reported with the use of heparin coated lenses. The safety of adding low molecular weight heparin to the infusion fluid during routine cataract surgery was investigated. Any direct antibacterial effect was looked for by culturing anterior chamber fluid samples taken at the completion of surgery.

Methods-A randomised, double blind, controlled study of 111 patients undergoing routine cataract surgery. Low molecular weight heparin at a concentration of 5 $I U / \mathrm{ml}$ was added to the infusion fluid in the trial patients. Samples from the anterior chamber taken at completion of surgery were cultured. Twenty nine samples of sterile infusion fluid were also cultured as further controls.

Results-No complications were found in either group, and no difference in observed postoperative inflammation in each group. In the heparinised group $(n=55)$ bacterial contamination was found in $31 \%$ of samples, compared with $27 \%$ in the no heparin group $(n=56)$ (no significant difference).

Conclusions-There appears to be no direct antibacterial effect of heparin, and other possible mechanisms of action are discussed. Heparin avoids many of the drawbacks of traditional antibiotic prophylaxis and may have the potential to be a safe and effective addition to endophthalmitis prevention.

(Br F Ophthalmol 1997;81:949-952)
\end{abstract}

Ophthalmology, West Norwich Hospital, Norwich

T D Manners

P H Galloway

A M Glenn

Public Health

Laboratory, West

Norwich Hospital,

Norwich

D P J Turner

Correspondence to:

Mr T D Manners, West

Norwich Hospital,

Bowthorpe Road, Norwich NR2 3TU.

Accepted for publication 28 April 1997 reduced bacterial adhesion to heparin coated lenses. This effect was also apparent when, in the same study, heparin in solution was incubated with the bacterial suspension and regular polymethylmethacrylate (PMMA) lenses. Direct antibacterial activity of heparin has not been reported, but this has not been tested for in vivo against the small numbers of non-virulent bacteria in the eye at completion of cataract surgery.

Heparinised intraocular infusions have been used in animal and human studies, particularly to inhibit fibrin formation following vitrectomy. ${ }^{5}$ An increased incidence of haemorrhage has been reported in vitrectomy, although animal studies using low molecular weight heparin suggest no significant effect on intraocular bleeding. ${ }^{6}$ Cataract surgery, unlike vitrectomy, is seldom complicated by any intraocular haemorrhage.

We aimed to demonstrate the safety of low molecular weight heparin added to the infusion solution used in routine phacoemulsification cataract surgery, and also to examine for any direct antibacterial effect by culturing a sample of anterior chamber fluid taken at the completion of surgery.

\section{Methods}

The study was designed to be prospective, randomised, double blind, and with equal numbers of trial and control patients. According to published guidelines, ${ }^{7}$ approximately $110 \mathrm{pa}-$ tients were required to achieve a power of $70 \%$, given a contamination rate of $30 \%$ and a reduction in contamination of $50 \%$ as clinically worthwhile. We also decided to send at least 20 second control specimens of sterile infusion fluid to test for laboratory contamination.

One hundred and eleven patients undergoing routine day case phacoemulsification cataract surgery were randomised into heparin and control groups. Written consent and ethics committee approval were obtained. Exclusion criteria included; (a) history or evidence of previous eye surgery or injury; (b) current or previous ocular inflammation; (c) perioperative complications such as posterior capsule rupture. All operations were done by one of two surgeons, with a standardised technique as follows.

Preoperative preparation included pupil dilatation with preservative free drops of cyclopentolate $1 \%$, phenylephrine $10 \%$, and maintenance of dilatation with diclofenac $0.1 \%$. Anaesthesia was topical in all cases (amethocaine 1\%), supplemented by a small subconjunctival bleb of lignocaine $2 \%$ at the incision site. Aseptic skin preparation consisted of washing the lids and surrounding skin with 
Table 1 Age/sex breakdowns of the heparin and no heparin groups

\begin{tabular}{lll}
\hline & Heparin $(n=55)$ & No heparin $(n=56)$ \\
\hline Mean age & 76.8 & 76.2 \\
Sex $(\mathrm{M} / \mathrm{F})$ & $15 / 40$ & $17 / 39$ \\
\hline
\end{tabular}

$7.5 \%$ povidone-iodine scrub. A single drop of aqueous povidone-iodine $5 \%$ was dropped into the inferior fornix and not rinsed. Clear adhesive Steridrape was applied. Routine four quadrant nucleofractis phacoemulsification followed. A $2.8 \mathrm{~mm}$ scleral pocket incision at 12 o'clock and separate paracentesis formed the entry sites, with the wound opened to 5 $\mathrm{mm}$ to accept a rigid one piece $5 \mathrm{~mm}$ PMMA lens. Temporal or on axis incisions for access or astigmatism were allowed. Viscoelastic was used and washed out at completion.

The standard irrigation fluid consisted of balanced salt solution (BSS) with adrenaline 1:100 000. The supplemented fluid consisted of low molecular weight heparin (Fragmin; Pharmacia) added to the standard fluid by a co-researcher or staff nurse to obtain a concentration of $5 \mathrm{IU} / \mathrm{ml}$.

No suture was used routinely and, after anterior chamber reformation, $0.1-0.2 \mathrm{ml}$ of anterior chamber fluid was removed via the paracentesis with a sterile 27 gauge cannula. Further reformation was then followed by subconjunctival cefuroxime injected into the superior bulbar area.

The aspirate was sealed and taken within 3 hours to the microbiology laboratory. Single drops of approximately $0.025 \mathrm{ml}$ were distributed in sequence from the syringe to chocolate blood agar (CBA) (incubated in 5\% carbon dioxide at $37^{\circ} \mathrm{C}$ ), brain-heart infusion broth (incubated at $37^{\circ} \mathrm{C}$ ), blood agar (ABA) (incubated anaerobically at $37^{\circ} \mathrm{C}$ ) and looped out using plastic disposable loops. If insufficient specimen remained to permit inoculation of the latter two media an equivalent volume of broth was drawn into the syringe, agitated, and distributed. The broth was subcultured at 24 hours to $\mathrm{CBA}\left(5 \%\right.$ carbon dioxide, $\left.37^{\circ} \mathrm{C}\right)$. All

Table 2 Details of positive cultures in the heparin group

\begin{tabular}{|c|c|c|c|}
\hline No & Organism & Medium & No of colonies \\
\hline 3 & Neisseria $\mathrm{sp}$ & broth & - \\
\hline 4 & CNS & broth & - \\
\hline 12 & CNS & ANA & 1 \\
\hline 19 & CNS & CBA + broth & 1 \\
\hline \multirow{2}{*}{21} & $S$ aureus + & CBA & 1 \\
\hline & $\mathrm{AnO}_{2} \mathrm{gpb}$ & broth & 1 \\
\hline 23 & $\mathrm{O}_{2} \mathrm{gpb}$ & CBA & 1 \\
\hline 29 & CNS & $\mathrm{ABA}$ & 1 \\
\hline 47 & $\mathrm{O}_{2} \mathrm{gpb}$ & CBA & 1 \\
\hline \multirow[t]{2}{*}{58} & $\mathrm{O}_{2} \mathrm{gpb}+\mathrm{CNS}$ & CBA & 1 \\
\hline & & $\mathrm{ABA}$ & 1 \\
\hline 59 & CNS & $\mathrm{ABA}$ & 1 \\
\hline 85 & CNS & $\mathrm{ABA}$ & 1 \\
\hline \multirow[t]{2}{*}{90} & Micrococcus sp & $\mathrm{ABA}+\mathrm{CBA}$ & 2 \\
\hline & & & 1 \\
\hline 92 & CNS & CBA + broth & 3 \\
\hline 96 & $\mathrm{O}_{2} \mathrm{gpb}$ & $\mathrm{CBA}$ & 1 \\
\hline 101 & CNS & $\mathrm{ABA}$ & 1 \\
\hline 104 & CNS & broth & - \\
\hline 111 & $\mathrm{AnO}_{2} \mathrm{gpb}$ & $\mathrm{ABA}$ & 1 \\
\hline
\end{tabular}

CNS = coagulase negative Staphylococcus $; \mathrm{O}_{2} \mathrm{gpb}=$ aerobic Gram positive bacillus; $\mathrm{AnO}_{2} \mathrm{gpb}=$ anaerobic $\mathrm{Gram}$ positive bacillus; $\mathrm{ABA}=$ blood agar (anaerobic); $\mathrm{CBA}=$ chocolate blood agar; broth = brain heart infusion broth. cultures were incubated for 5 days and examined regularly for growth. Colony numbers were noted if the direct culture was positive, or 'broth' stated if broth culture only was positive. Colonies were subcultured to blood agar for identification by standard microbiological methods.

In addition to the above samples, 29 specimens of sterile balanced salt solution were sent in indistinguishable containers to the laboratory to test for the possibility of contamination of the ocular samples after surgery.

Patients were examined the day after surgery and any complications were noted. Fibrin and cells in the anterior chamber were graded according to the system of Hogan et al. ${ }^{8}$ Intraocular pressure (IOP) was recorded. A second examination took place 1-2 weeks after surgery at which best corrected visual acuity was recorded, and if all was well, the patient was discharged at that point.

\section{Results}

All patients enrolled completed the trial. Age/sex breakdowns of each group are given in Table 1. There were no perioperative or postoperative complications which resulted in exclusion, and in particular, there was no case of suspected or frank infection. There were no cases of untoward bleeding in either group. All patients were either discharged or listed for the other eye at the 1-2 week follow up, with the exception of patients with coincident eye disease (for example, glaucoma or diabetic eye disease). Clinically graded cell counts in the anterior chamber on day 1 varied from zero to $2+$ of cells. Mean count was 0.49 in both the heparin and no heparin groups (no difference). There were only two patients overall with any clinically measurable flare postoperatively, one from each group. The mean day 1 intraocular pressure was 20.3 in the heparin group (SD 5.1), and 19.9 in the no heparin group (SD 3.8). There is no statistical significance in this difference (Student's $t$ test $\mathrm{p}=>0.5$ ).

Full details of bacterial growth are detailed in Tables 2 and 3. Overall, 32 specimens out of 111 grew organisms $(28.8 \%)$. Of the plated samples, the commonest organisms were coagulase negative staphylococci, followed by aerobic Gram positive bacilli (diphtheroid bacilli) and anaerobic Gram positive bacilli (assumed to be mostly Propionibacterium species). The number of colonies found were one per sample in nearly all cases.

In all, $30.9 \%$ of the heparinised samples grew bacteria, compared with $26.8 \%$ from the no heparin group. There is no statistical significance in this difference $\left(\chi^{2}=0.23, \mathrm{p}=\right.$ $>0.5)$. The sterile control samples grew bacteria in three of 29 samples $(10.3 \%)$. The difference between this group and both the trial groups is statistically significant $\left(\chi^{2}=4.19, \mathrm{p}=\right.$ $<0.05)$.

\section{Discussion}

This study reveals no untoward side effects when using low molecular weight heparin in this dose inside the eye during cataract surgery. In particular, there were no incidences of peri- 


\begin{tabular}{|c|c|c|c|}
\hline No & Organism & Medium & No of colonies \\
\hline \multirow[t]{2}{*}{1} & \multirow[t]{2}{*}{$\mathrm{CNS}+\mathrm{AnO}_{2} \mathrm{gpb}$} & CBA & 1 \\
\hline & & $\mathrm{ABA}$ & 1 \\
\hline 5 & $\mathrm{AnO}_{2} \mathrm{gpb}$ & $\mathrm{ABA}$ & 1 \\
\hline 8 & $\mathrm{CNS}+\mathrm{O}_{2} \mathrm{gpb}$ & $\begin{array}{l}\text { ABA } \\
\text { broth }\end{array}$ & 1 \\
\hline 10 & CNS & $\mathrm{ABA}$ & 2 \\
\hline 14 & $\mathrm{AnO}_{2} \mathrm{gpb}$ & $\mathrm{ABA}$ & 1 \\
\hline \multirow[t]{2}{*}{26} & \multirow[t]{2}{*}{$\mathrm{O}_{2} \mathrm{gpb}+\mathrm{CNS}$} & CBA & 1 \\
\hline & & CBA & 1 \\
\hline 28 & $\mathrm{O}_{2} \mathrm{gpb}$ & $\mathrm{CBA}$ & 1 \\
\hline 30 & $\mathrm{AnO}_{2} \mathrm{gpb}+\mathrm{CNS}$ & ABA & 1 \\
\hline 7 & CNS & $\mathrm{CBA}$ & 1 \\
\hline \multirow[t]{2}{*}{43} & CNS + & CBA & 1 \\
\hline & Bacillus sp & CBA & 1 \\
\hline 57 & $\mathrm{CNS}$ & $\mathrm{ABA}$ & 1 \\
\hline 68 & $\mathrm{O}_{2} \mathrm{gpb}$ & CBA & 2 \\
\hline 91 & $\mathrm{AnO}_{2} \mathrm{gpb}$ & $\mathrm{ABA}$ & 1 \\
\hline 97 & $\mathrm{CNS}$ & CBA & 1 \\
\hline 108 & CNS & CBA & 1 \\
\hline
\end{tabular}

operative or postoperative haemorrhage. The dose of $5 \mathrm{IU} / \mathrm{ml}$ was chosen from work which showed this concentration to be effective at preventing postoperative fibrin formation in animal models. ${ }^{9}$ This concentration was also shown to cause a trend towards reduced intraocular fibrin formation in a study on human eyes during vitrectomy. ${ }^{5}$ A concentration of $10 \mathrm{IU} / \mathrm{ml}$ significantly reduced fibrin formation but caused increased intraoperative bleeding. Both concentrations are several times higher than the plasma concentration achieved during routine therapeutic anticoagulation, but it appears from animal models that the eye needs a higher concentration to inhibit the coagulation cascade. ${ }^{56}$ Low molecular weight heparin was used as this fraction causes less haemorrhage for a similar anticoagulant dose when compared with unfractionated preparations. This is because of a less adverse effect on platelet function than with the other preparations. ${ }^{6}$

This study showed no heparin effect on postoperative intraocular inflammation as judged clinically, but the degree of inflammatory signs is so low after routine phacoemulsification that this tells us little. A study published in Germany after this trial was completed ${ }^{10}$ measured postoperative flare with laser photometry after heparinising the anterior chamber during surgery and found reduced flare in the heparin group. Heparin from animal sources was used at a concentration of 10 $\mathrm{IU} / \mathrm{ml}$, and no complications were attributed to the heparin.

We have also shown the frequently confirmed contamination of the anterior chamber by small numbers of bacteria at the completion of surgery. ${ }^{11}{ }^{12}$ Our incidence of contamination (about 30\%) is similar to previous UK studies, and the same numbers and types of organisms were found. Although there is no proof that these are the bacteria that can cause infection, they are the same groups of organisms that cause endophthalmitis (predominantly coagulase negative staphylococci) and they are in the right place at the right time. These bacteria are widespread on the eyelids, and in cases of frank infection, the causative organisms have been genetically typed to the patients own lid flora. ${ }^{13}$
The incidence of contamination of sterile samples is interesting. The most likely site of contamination is the plates in the laboratory. As these skin organisms are present so ubiquitously and this sort of study looks for such small numbers of bacteria, it is important that this background level is measured. Only one previous study on anterior chamber contamination has done this. ${ }^{14}$

The role of heparin in the prevention of endophthalmitis is still unclear. This study goes some way to confirming that there is no direct antibacterial effect on the organisms in the eye at completion of surgery (subject to the power limitations of the study). It has been suggested that heparin could have an effect either by coating a surface (and preventing bacterial adherence to this surface), or by coating the bacteria, and thus again preventing adherence. ${ }^{4}$ Bacterial adherence is reduced both on heparin coated lenses and on lenses incubated with bacteria in suspension with heparin. ${ }^{4}$ As the heparin is tightly and permanently ${ }^{15}$ bound to the lens in the coated lens it is not free to coat the bacteria, and is thought to work by trapping a layer of water molecules to its hydrophilic long arms extending from the IOL surface, thus preventing bacterial access. On the other hand, the heparin in solution would not be expected to coat the hydrophobic PMMA lens and yet still has an effect, so perhaps another mechanism is important. Experimental proof is lacking, but it is likely that the heparin interferes with the binding sites on the bacterial surface and therefore prevents adherence to the lens. ${ }^{4}$ If this is the case, then heparin in solution could have a greater effect on endophthalmitis prevention than heparin coated IOLs, as the heparin would inhibit bacterial binding to other recesses in the eye, such as the capsular bag or soft lens matter remnants. In addition, any beneficial effects of heparin in solution and heparin coated IOLs on the incidence of endophthalmitis would be expected to be additive. Similar studies on bacterial adherence to contact lenses have already led to a recommendation for heparin to be used in contact lens solutions. ${ }^{16}$

Gills has been including heparin in solution at a concentration of $1.6 \mathrm{IU} / \mathrm{ml}$ in his antibiotic/BSS solution and has stated a series of 27000 cases without endophthalmitis or complications related to the irrigating solution. ${ }^{17}$ His rationale behind inclusion of heparin is unstated and no full publication of his results has followed.

In a recent editorial on endophthalmitis prevention the dangers of routine preventive antibiotic use (particularly of vancomycin use causing bacterial resistance) were stressed. ${ }^{18}$ The use of antibiotics in the infusion has been criticised owing to the lack of effect of short term exposure to antibiotics on the organisms, ${ }^{19}$ and also the cost. Current advice on endophthalmitis prevention focuses on physical measures, competent surgery, use of povidone-iodine, and acknowledges a possible though unproved role for perioperative topical or subconjunctival antibiotics. 
Further publication on the effect of heparin coated IOLs on the incidence of endophthalmitis is awaited, and should be available given the large numbers of these lenses used worldwide. A multicentre prospective study on the use of heparin in solution is receiving consideration in the UK. At present the data do not support routine use of heparin, but if further study confirms a role, then it does at least have the advantages of being cheap, available, non-toxic, and not provoking bacterial resistance.

We acknowledge and thank Pharmacia UK Ltd for the supply of Fragmin, and for their support towards the microbiology costs.

1 Hughes DS, Hill RJ. Infectious endophthalmitis after cataract surgery

Tong term results and biocompatability of heparin surface modified intraocular lenses. $\mathcal{F}$ Cataract Refract Surg 1993;19:258-62.

3 Ocular Surgery News 1993; vol 11: no 21

4 Portoles M, Refojo M, Leong F. Reduced bacterial adhesion to heparin-surface-modified intraocular lenses. 7 Cataract to heparin-surface-modified

5 Johnson RN, Blankenship G. A prospective, randomised trial of heparin therapy for postoperative intraocular fibrin. Ophthalmology 1988;95:312-7.

6 Iverson DA, Katsura H, Hartzer MK, Blumenkranz MS Inhibition of intraocular fibrin following infusion of low-molecular-weight heparin during vitrectomy. Arch Ophthalmol 1991;109:405-9.
7 Boag JW, Haybittle MA, Fowler JF, Emery EW. The number of patients required in a clinical trial. Br f Radiol 1971;44: of patients.

8 Hogan MJ, Kimura SJ, Thygeson P. Signs and symptoms of uveitis. 1 Anterior uveitis. Am $\mathcal{F}$ Ophthalmol 1959;47:15570 .

9 Johnson RN, Balyeat BA, Stern WH. Heparin prophylaxis for intraocular fibrin. Ophthalmology 1987;94:597-601.

10 Kohnen T, Dick B, Hessemer V, Jacobi KW. Antiinflammatory effect of infusion solution with heparin during phakoemulsification. Ophthalmologe 1995;92:297-302.

11 Manners TD, Chitkara DK, Marsh PJ, Stoddart MG. Anterior chamber aspirate cultures in small incision cataract surgery. Br f Ophthalmol 1995;79:878-80.

12 Sherwood DR, Rich WJ, Jacob JS, Hart RJ, Fairchild YL. Bacterial contamination of intraocular and extraocular fluids during extracapsular cataract extraction. Eye 1989;3: ids durin

13 Speaker MG, Milch FA, Shah MK, Eisner W, Kreiswith BN. Role of external bacterial flora in the pathogenesis of acute postoperative endophthalmitis. Ophthalmology 1991; 97:639-50.

14 Assalian A, Thompson P, St-Antoine P, Lemire J, Duperre J, Demers J-P, et al. Anterior chamber fluid contamination after uncomplicated phakoemulsification. 7 Cataract Refract Surg 1995;21:539-42.

15 Larson R, Selen G, Formgren B, Holst A. Long term stability of heparin-surface-modified intraocular lenses in vivo. $\mathcal{F}$ Cataract Refract Surg 1992;18:247-51.

16 Duran JA, Malvar A, Rodriguez-Ares MT, Garcia-Riestra C. Heparin inhibits pseudomonas adherence to soft C. Heparin inhibits pseudomo
contact lenses. Eye 1993;7:152-4.

17 Gills JP. Letter. F Cataract Refract Surg 1993;18:109.

18 Alfonso CA, Flynn HW. Controversies in endophthalmitis prevention. (Editorial) Arch Ophthalmol 1995;113:136970 .

19 Gritz DC, Cevallos AV, Smolin G, Whitcher JP. Antibiotic supplementation of intraoperative infusions - an in vitro model. Invest Ophthalmol Vis Sci 1995;36: supp154, ARVO abstracts 